\title{
CHIẾN LƯợC KHÔNG SỦ DỤNG MÁU TRONG TUÀ̀ HOÀN NGOÀI CƠ THỂ Ở PHẪU THUẠTT TIM TRẺ EM
}

Đoàn Đức Hoằng* Nguyễn Lương Tấn**

\section{TÓM TẮT}

Không sử dụng máu hoặc chế phẩm máu trong tuần hoàn ngoài cơ thể để phẫu thuật tim cho trẻ em có cân nặng trên $15 \mathrm{~kg}$ có thể được thực hiện một cách an toàn và đạt kết quả tốt. Khi phối hợp với một loại phổi nhân tao (oxygenator) có thể tích đổ đầy thấp với hệ thống tuần hoàn ngoài cơ thể cải tiến này đã hạn chế nhu cầu truyền máu và chính nhờ điều kiện này mà chúng

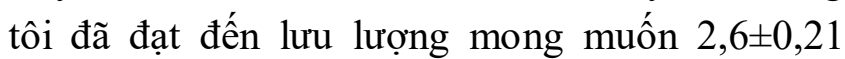
$\mathrm{L} / \mathrm{min} / \mathrm{m}^{2}$ và vẫn đạt được nồng độ thể tích huyết cầu hematocrit từ $28 \%$ đến $36 \%$.

Tù khóa: cardiopulmonary bypass (CPB), congenital heart disease (CHD).

\section{SUMMARY}

STRATEGIES FOR BLOODLESS PRIMING

IN CARDIOPULMONARY BYPASS IN PEDIATRIC CARDIAC SURGERY

Bloodless pediatric cardiac surgery in patients over $15 \mathrm{~kg}$ in weight can be performed safely. Incorporating a lower prime oxygenator into a revised circuit alleviated the need for blood transfusion and allowed us to achieve our calculated flow rate of $2.6 \pm 0.21 \mathrm{~L} / \mathrm{min} / \mathrm{m}^{2}$ while maintaining a hematocrit range from $28 \%$ to $36 \%$.

Keywords: cardiopulmonary bypass (CPB), congenital heart disease (CHD).

\section{I. ĐẶT VẤN ĐỀ}

Phẫu thuật tim hở dưới tuần hoàn ngoài cơ thể mà không cần sử dụng máu hoặc các chế phẩm máu (bloodless surgery - phẫu thuật không sử dụng máu) đang là thách thức lớn đối với người làm tuần hoàn ngoài cơ thể, nhất là trong lĩnh vực phẫu thuật tim trẻ em [1] và càng nghiêm ngặt hơn cho nhóm tuổi này nhưng có niềm tin vàođạo giáo Jehovah's Witness [2,3]. Mục tiêu không truyền máu và hạn chế nhu cầu sử dụng các chế phẩm máu hoặc các yếu tố đông máu trong quá trình phẫu thuật tim trẻ em có thể khó mà đạt được nếu như có sự pha loãng máu quá mức trong tuần hoàn ngoài cơ thể, mà điều này là rất thường gặp ở bệnh nhân trẻ em [2,3]. Pha loãng máu do bởi sử dụng một thể tích mồi (priming) quá lớn để làm đầy hệ thống tuần hoàn ngoài cơ thể đối nghịch với một thể tích tuần hoàn vốn khiêm tốn ở trẻ em cũng như mất máu trong quá trình phẫu thuật càng gây pha loãng nhiều hơn.

Trong nghiên cứu này, chúng tôi trình bày chiến lược làm giảm thể tích priming ở trẻ em có cân nặng trên $15 \mathrm{~kg}$ có chỉ định phẫu thuật tim hở để sửa chữa các khuyết tật bẩm sinh trong tim như thông liên nhĩ, thông liên thất, hẹp động mạch phổi, thất phải hai đường ra, kênh nhĩ thất bán phần hay toàn phần, tứ chứng Falot ...

\section{PHƯƠNG PHÁP VÀ KẾT QUẢ NGHIÊN CÚU}

Tám mươi sáu bệnh nhân trẻ em mắc bệnh tim bẩm sinh có cân nặng trong khoảng $15-20 \mathrm{~kg}$ được chỉ định phẫu thuật từ tháng 04/2016 đến tháng 12/2018 tại Bệnh viện Đa khoa Quốc tế Vinmec Central Park để sửa chữa khuyết tật như thông liên nhĩ, thông liên thất, thất phải hai đường ra, kênh nhĩ thất bán phần hoặc toàn phần,

* Bệnh viện Đa khoa Tâm Trí Sài Gòn

** Bệnh viện Đa khoa Quốc tế Vinmec Central Park Nguoòi chịu trách nhiệm khoa học: TS.Đoàn Đíc Hoằng

Ngày nhận bài: 01/02/2019 - Ngày Cho Phép Đăng: 23/03/2020

Phản Biện Khoa học: PGS.TS. Đăng Ngọc Hùng GS.TS. Lê Ngoc Thành 
hẹp động mạch phổi, tứ chứng Falot... Những bệnh nhân trẻ em này có cân nặng trung bìnhlà $18,7 \pm 1,9 \mathrm{~kg}$, chiều cao trung bình là $109 \pm 11 \mathrm{~cm}$, và có diện tích cơ thể trung bình là $0,75 \pm 0,07 \mathrm{~m}^{2}$.

Các tiêu chí đặt ra là không sử dụng máu hoặc các chế phẩm máu trong quá trình phẫu thuật và cả giai đoạn sau mổ nhưng hệ thống được trang bị tiện nghi với máy thu hồi hồng cầu cell-saver được sử dụng liên tục trong quá trình phẫu thuật. theo protocol tại bệnh viện của chúng tôi, mức trung bình lưu lượng tuần hoàn ngoài cơ thể cần đạt là $1,9 \pm 0,15$ lít/phút tương ứng với mức trung bình của chỉ số tim là $2,6 \pm 0,24$ lít/phút $/ \mathrm{m}^{2}$ và mức thấp nhất về giá trị hematocrit (Hct) ước tính trong quá trình tuần hoàn ngoài cơ thể là $28 \%$. Ngưỡng thấp nhất về giá trị Hct = $28 \%$ trong điều kiện tuần hoàn ngoài cơ thể là khả dĩ chấp nhận theo protocols tại trung tâm của chúng tôi. Giá trị trung bình về thể tích máu ước tính của nhóm bệnh nhân nghiên cứu là $1496 \pm 102 \mathrm{~mL}$.Giá trị trung bình về nồng độ hemoglobin trước mổ là $11,6 \pm 0,12 \mathrm{~g} / \mathrm{dL}$ và giá trị trung bình Hct trước mổ là $36 \pm 2,6 \%$.
Cấu hình thường qui về hệ thống dây dẫn tuần hoàn ngoài cơ thể của chúng tôi sử dụng cho bệnh nhân trẻ em có cân nặng từ $15 \mathrm{~kg}$ trở lên phải cần một thể thích priming là $315 \mathrm{~mL}$ (bảng 1 ) và như vậy giá trị trung bình về Hct sau khi pha loãng máu sẽ đạt $28 \pm 3,1 \%$ khi khởi đầu tuần hoàn ngoài cơ thể. Trong khi mực tiêu của chúng tôi cần đạt mức giá trị này $\mathrm{Hct}>28 \%$, điều này có nghĩa rằng hệ thống dây dẫn cần phải được cải tiến.Chúng tôi trình bày mộ số phương pháp thực hiện để giảm thiểu thể tích priming và những kết quả đạt được như sau:

Thông thường, chúng tôi sử dụng cỡ dây 3/8-inch để dẫn máu tĩnh mạch và cỡ dây $1 / 4$ inch để dẫn máu động mạch. Tuy nhiên, chúng tôi cải tiến hệ thống bằng cách giảm cỡ dây $1 / 4$-inch để dẫn máu tĩnh mạch với điều kiện có gắn hệ thống hút hỗ trợ thêm dẫn lưu máu tĩnh mạch với áp lực rất nhẹ $(-5 \mathrm{mmHg})$ nhằm cải thiện hồi lưu máu tĩnh mạch [4]. Việc cải thiện hệ thống tuần hoàn ngoài cơ thể như vậy đã giúp rút giảm thể tích priming từ $315 \pm 25 \mathrm{~mL}$ giảm xuống còn $210 \pm 15 \mathrm{~mL}$ (bảng 1).

Bảng 1. Những khác biệt giữa hệ thống tuần hoàn ngoài cơ thể thường qui và cải tiến.

\begin{tabular}{|l|l|l|}
\hline Loại vật tư y tế & Hệ thống thường qui & Hệ thống cải tiến \\
\hline Oxygenator & Dideco D101(87 $\mathbf{~ L ~})$ & Medtronic Affinity Pixie $(\mathbf{4 8} \mathbf{~ m L})$ \\
\hline Bầu lọc động mạch & Dideco D 131(28 $\mathbf{~ L ~})$ & None \\
\hline $\begin{array}{l}\text { Kích cỡ dây dẫn máu } \\
\text { động - tĩnh mạch }\end{array}$ & $1 / 4-\mathbf{3 / 8}$ inch & $1 / 4-\mathbf{1} / \mathbf{4}$ inch \\
\hline Cỡ dây qua bơm máu & $1 / 4$ inch & $1 / 4$ inch \\
\hline Thể tích priming & $\mathbf{3 1 5} \mathbf{~} \mathbf{L}$ & $\mathbf{2 1 0} \mathbf{~ m L}$ \\
\hline
\end{tabular}

- Phổi nhân tạo (oxygenator) Affinity Pixie (Medtronic Inc., Minneapolis, MN) được sử dụng cho tất cả 86 bệnh nhân trong nhóm nghiên cứu có cấu hình rất phù hợp như thể tích priming tĩnh rất thấp là $48 \mathrm{~mL}$ nhưng có mức giới hạn lưu lượng khá cao lên đến2,0 lít/phút. Sử dụng loại oxygenator Affinity Pixie thay thế loại oxygenotor thường qui Dideco 101 (Sorin Group, Milan, Italy), vì loạn này vốn có thể tích priming tĩnh là cao hơn là $87 \mathrm{~mL}$. Chúng tôi sử dụng dung 
dịch Plasma-Lyte A (Baxter Healthcare Corporation, Deerfield, IL) là loại dung dịch tinh thể để priming solution đồng thởi sử dụng thuốc kháng đông 1100 đơn vị heparin đồng thời 6$10 \mathrm{mEq}$ sodium bicarbonate. Liều lượng mannitol được sử dụng từ 2,2-2,5g được sử dụng ngay sau khi khởi đầu tuần hoàn ngoài cơ thể. Chúng tôi hạn chế sử dụng albumin trong priming cũng như ngay cả khi cần bù thể tích sau mổ bởi vì những báo cáo về albubin có liên quan đến các biến chứng về tổn thương thận cấp và chảy máu sau mổ [5].

- Quá trình đặt các cannula động mạch sử dụng loại DLP aortic cannula (Medtronic Inc., Minneapolis, $\mathrm{MN}$ ) có kích cỡ từ $12 \mathrm{~F}-14 \mathrm{~F}$ và đặt 2 cannula tĩnh mạch có kích cỡ 16 F - 18 F. Sử dụng loại máy tim phổi nhân tạo Stockert System (Stockert Cardiovascular) với các đầu bơm có thể di chuyển linh hoạt.

- Đối với nhóm bệnh nhân trẻ em có cân nặng từ $15 \mathrm{~kg}$ trở lên, thông thường chúng tôi sử dụng loại đầu bơm cỡ lớn đòi hỏi sử dụng đoạn dây dẫn máu qua vòng con lăn phải dài tương ứng nhưng nhằm giảm thể tích priming, chúng tôi thử nghiệm sử dụng đầu bơm cỡ nhỏ để giúp rút ngắn đoạn dây dẫn máu qua bơm. Với phương thức nhằm làm giảm thể tích priming, đoạn dây dẫn máu qua bơm kết nối ở đầu mấy máu ra từ reservoir đến đầu bơm máu vào oxygenator được cắt giảm chiều dài xuống còn26 $\pm 1,4$ inches so với chiều dài thường qui là $33 \pm 2,2$ inches.

- Các đầu bơm sử dụng với mục đích hút máu từ phẫu trường hoặc để hút máu trong các buồngtim đều được sử dụng loại có kích cỡ nhỏ. Vị trí các đầu bơm này được sắp xếp thích hợp sao cho gần với bàn mổ nhất và làm rút ngắn kích thước các đoạn dây dẫn máu hút về phổi nhân tạo. Chúng tôi sử dụng loại dây dẫn máu có kích cỡ nhỏ 1/4-inch cho tất cả các bơm hút máu về ngoại trừ sử dụng loại dây dẫn máu để hút trong động mạch chủ có kích cỡ nhỏ hơn thường qui có đường kính là $1 / 8$-inch để tránh mất thể tích nhiều từ hệ thống tuần hoàn ngoài cơ thể vì lý do luôn phải duy trì đầy máu đoạn dây dẫn máu này trong thì đuổi khí chuẩn bị để tim hoạt động trở lại sau khi đã kết thúc các thao tác phẫu thuật sửa chữa. Chúng tôi cũng đã nghĩ đến phương án sử dụng loại cỡ dây 3/16-inch sử dụng cho các dây dẫn hút máu trở về nhưng sẽ có nguy cơ gây huyết tán nhất là trong những ca phẫu thuật tim bẩm sinh có tuần hoàn bàng hệ nhiều đòi hỏi tốc độ hút lớn hơn bình thường.

- Đối với các loại oxygenator có thiết kế phù hợp như Affinity Pixie, và nhất là những loại oxygenator được thiết kế tích hợp màng lọc động mạch bên trong oxygenator, thì việc loại bỏ bầu lọc bên ngoài ra khỏi hệ thống tuần hoàn ngoài cơ thể sẽ giúp giảm priming $28 \mathrm{~mL}$ (thể tích mồi để làm đầy bầu lọc độc mạch bên ngoài). Các bác sĩ cần đảm bảo việc giải thích trang bị cho các bậc cha mẹ và người thân của bệnh nhân phải nhận thức về quá trình phẫu thuật và chiến lược không sử dụng máu trong quá trình làm tuần hoàn ngoài cơ thể. Tuy nhiên, bệnh viện của chúng tôi luôn có sẵn quy trình dự phòng cho phép thực hiện một cách nhanh nhất để nhận và truyền máu trong những tình huống khẩn cấp [2].

- Vào thời điểm phẫu thuật viên thiết lập hệ thống tuần hoàn ngoài cơ thể thông qua cầu nối động mạch - tĩnh mạch, cần phải cắt bớt một đoạn dây dẫn máu để rút ngắn nhất đoạn cầu nối này, qua đó, giúp làm giảm một thể tích $33 \pm 2,3 \mathrm{~mL}$. Sau khi đã kết nối các cannulas tĩnh mạch vào dây dẫn máu, chúng tôi còn thao tác rút bớt dung dịch priming từ hệ thống với thể tích tương đương $23 \pm 2,0 \mathrm{~mL}$ ngay trước khi vận hành tuần hoàn ngoài cơ thể sau khi người phẫu thuật viên đã mở clamp đường tĩnh mạch. như vậy, việc cắt ngắn đoạn cầu nối động - tĩnh mạch và sau thao tác rút bớt dung dịch priming ngay trước khởi đầu tuần hoàn ngoài cơ thể đã giúp rút giảm thể tích priming (vốn đã giảm từ $315 \mathrm{~mL}$ xuống 
còn $210 \mathrm{~mL}$ ) và nhờ thủ thuật này chúng tôi đã giảm thêm tiếp tục thể tích mồi từ $210 \pm 15 \mathrm{~mL}$ to $160 \pm 15 \mathrm{~mL}$.

- Về kết quả, nhóm bệnh nhân nghiên cứu có giá trị trung bình chỉ số hematocrit (Hct) trước mổ là $36 \pm 2,6 \%$. Thời gian trung bình thực hiện tuần hoàn ngoài cơ thể cho nhóm bệnh nhân này là $55 \pm 9$ phút. Mức thấp nhất về giá trị Hct là $24 \pm 1,2 \%$, xảy ra vào thời điểm ngay sau sử dụng dung dịch Custodial Bretschneider HTK (Essentials Pharm, Newtown, PA)để làm liệt tim. Mức cao nhất về giá trị Hct là $30 \pm 1,9 \%$. Chúng tôi sử dụng loại quả lọc máu HPH 400 (Minntech Mini, Minneapolis, $\mathrm{MN}$ ) nhằm mục đích lọc bỏ lượng dịch thừa và quả lọc này được thiết kế sẵn trong hệ thống nhưng không cần prming cho đến khi khởi động tuần hoàn ngoài cơ thể. Kết quả phân tích nồng độ các chất khí trong mẫu máu thử vào thời điểm sau khi kết thúc sử dụng protamine có mức giá trị về Hct là $32 \pm 3,4 \%$. Ngoài ra, sau khi kết thúc tuần hoàn ngoài cơ thể, chúng tôi thu hồi thêm một thể tích máu lấy từ dây dẫn máu tĩnh mạch bằng cách thay thế vào đoạn dây này bằng một thể tích tương đương dung dịch Plasma Lyte A (Baxter Healthcare Corporation). Thể tích máu thu hồi này được truyền trở lại cho bệnh nhân giúp nâng cao hơn nữa mức giá trị Hct.

- Nhóm bệnh nhân nghiên cứu được chuyển về phòng hồi sức sau mổ có mức giá trị trung bình về Hct là $33 \pm 3,1 \%$, được điều trị huyết động ổn định, cai thở máy và có mức trung bình về thời gian thở máy sau mổ là $4 \pm 0,8$ giờ. Không có biến chứng tiểu máu xảy ra ở giai đoạn trong mổ hoay sau mổ. Kết quả phân tích nồng độ các chất khí trong máu có giá trị các thông số đều trong giới hạn bình thường và không có biểu hiện của tình trạng toan chuyển hóa. Nồng độ lactate máu ở giai đoạn sau mổ có giá trị trung bình là $1,4 \pm 0,2 \mathrm{mmol} / \mathrm{L}$, và nồng độ creatinine huyết thanh có giá trị trung bình là $47 \pm 5,1 \mu \mathrm{mol} / \mathrm{L}$. Lượng máu mất đo qua ống dẫn lưu ngực ở giai đoạn sau mổ có mức giá trị trung bình là $75 \pm 9,5$ $\mathrm{mL}$. Không có truyền máu hoặc các chế phẩm máu ở giai đoạn sau mổ và tất cả các bệnh nhân trong nghiên cứu đều được xuất viện và có thời gian nằm viện trung bình là $4 \pm 1$ ngày với mức giá trị trung bình về Hct là $32 \pm 2,0 \%$.

\section{BÀN LUẬN}

Với mục đích làm giảm hậu quả pha loãng máu do hệ thống tuần hoàn ngoài cơ thể, chúng tôi có thể khẳng định rằng tuần hoàn ngoài cơ thể không sử dụng máu có thể đảm bảo an toàn khi phẫu thuật tim ở trẻ em trong nhóm cân nặng từ $15-20 \mathrm{~kg}$, và kỹ thuật này đặc biệt phù hợp cho các bệnh nhân không muốn nhận bất kỳ chế phẩm máu nào. Tại bệnh viện của chúng tôi, thể tích priming sử dụng trong tuần hoàn ngoài cơ thể cho nhóm bệnh nhân có cân nặng từ 2-14 kg là 170$205 \mathrm{~mL}$. Đối với những bệnh nhân có cân nặng từ $15 \mathrm{~kg}$ trở lên thì cần một hệ thống có kích thước lớn hơn, cho nên cần bổ sung thêm một thể tích là $105 \mathrm{~mL}$ vào thể tích priming.

Với các loại oxygenator có thể tích priming nhỏ, các loại máy tim phổi có thể điều chỉnh vị trí các đầu bơm hướng gần đến phẫu trường, và việc sử dụng loại dây dẫn máu tĩnh mạch có kích cỡ nhỏ trong điều kiện an toàn nhờ hệ thống hút nhẹ để hỗ trợ hồi lưu máu tĩnh mạch, thì chúng tôi đã rút giảm thể tích priming, và các kỹ thuật này giúp làm giảm hậu quả pha loãng máu trên các bệnh nhân. Việc cắt giảm hệ thống dây dẫn còn giúp duy trì lượng máu dồn về reservoir nhiều hơn, do đó sẽ có thể tích đưa dòng máu đi qua bầu cô đặc máu, vì vậy đến lúc kết thúc tuần hoàn ngoài cơ thể sẽ đạt được mức Hct cao hơn. Việc phối hợp nhiều phương thức nêu trên đã hạn chế được việc sử dụng máu hoặc các chế phẩm máu, qua đó giúp tiết kiệm đáng kể, và quan trọng nhất 
là đạt được kết quả cho các bệnh nhân trẻ em trước khi chuyển ra khỏi phòng mổ tim có mức Hct khá cao đủ để tránh nhu cầu truyền máu ở giai đoạn sau mổ.

Ngoài ra, việc sử dụng cỡ dây $1 / 8$-inch để hút máu trong buồng tim là một yếu tố chính trong việc duy trì thể tích tuần hoàn.Kỹ thuật siêu lọc máu liên tục là rất hữu ích để lọc bổ sung lượng dịch thừa trong quá trình tuần hoàn ngoài cơ thể. Việc thiết kế tích hợp bộ phận siêu lọc cải tiến vào hệ thống tuần hoàn chung đang là một thách thức đáng kể vì cần thiết sử dụng thêm một thể tích vào để priming trong khi mục tiêu là hạn chế thể tích vào giai đoạn kết thúc tuần hoàn ngoài cơ thể.Mục tiêu nền tảng là thực hiện nhiều nhất có thể những ca phẫu thuật tim không sử dụng máu cho đối tượng bệnh nhân trẻ em.Tiếp sau nghiên cứu này, chúng tôi cũng sẽ áp dụng những cách thức tương tự nhưng vẫn thiết kế thêm một bầu lọc động mạch vào hệ thống cho những bệnh nhân trẻ em có cân nặng từ $15 \mathrm{~kg}$ trở lên, và ngay thời điểm hiện tại chúng tôi cũng đã thực hiện đến khoảng $60 \%$ trong tổng số các ca mổ tim hở là không sử dụng máu, ngay cả cho những ca mổ tim có nhiều nguy cơ mất máu như phải mổ nhiều lần.

\section{KẾT LUẬN}

Phẫu thuật tim trẻ em có cân nặng trên 15 $\mathrm{kg}$ trong đó kỹ thuật tuần hoàn ngoài cơ thể không sử dụng máu vẫn có thể được thực hiện một cách an toàn. Việc kết hợp sử dụng loại oxygenator có thể tích priming nhỏ với hệ thống dây dẫn máu tuần hoàn ngoài cơ thể kiểu cải tiến giúp hạn chế nhu cầu truyền máu và cho phép chúng tôi đạt được lưu lượng tối ưu trong tuần hoàn ngoài cơ thể với mức giá trị trung bình là

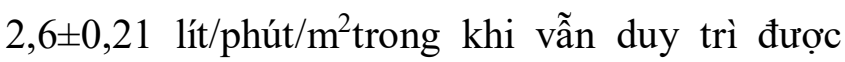
biến thiên giá trị hematocrit trong khoản an toàn từ $28 \%$ - 36\%.Tất cả các bệnh nhân trong nghiên cứu đều xuất viện sớm và có thời gian nằm viện trung bình là $4 \pm 1$ ngày và đạt mức giá trị trung bình về Hct là $32 \pm 2,0 \%$.

\section{TÀI LIỆU THAM KHẢO}

1. Miyaji KA, Kohira SA, Miyamoto TA, et al. Pediatric cardiac surgery without homologous blood transfusion, using a miniaturized bypass system in infants with lower body weight. J Thorac Surg. 2007;134:284-9.

2. Forest RJ, Groom RC, Quinn R, Donnelly J, Clark C. Repair of hypoplastic left heart syndrome in a $4.25 \mathrm{~kg}$ Jehovah's Witness. Perfusion. 2002;17:221-5.

3. Karimi MO, Florentino-Pineda IV, Weatherred TE, et al. Blood conservation operations in pediatric cardiac patients: A paradigm shift of blood use. Ann Thorac Surg. 2013;95:962-7.

4. Nakanishi K, Shichijo T, Shinkawa Y, et al. Usefulness of vacuum-assisted cardiopulmonary bypass circuit for pediatric open-heart surgery in reducing homologous blood transfusion. Eur J Cardiothorac Surg. 2001;20:233-8.

5. Utley JR, Stephens DB, Wachtel C, et al. Effect of albumin and mannitol on organ blood flow, oxygen delivery, water content and renal function during hypothermic hemodilution cardiopulmonary bypass. Ann Thorac Surg. 1982;33:250-7. 